\title{
Pendidikan Tauhid Dalam Kisah Nabi Ibrahim
}

\author{
Alfrida Dyah Septiyani \\ Institut Agama Islam Negeri (IAIN) Salatiga
}

\begin{abstract}
The results showed that: 1) Monotheism Education in Surat Al-An'am: 74-83 namely: 1) Monotheism Education Rubübiyah, which is in verse 75 which explains that Allah SWT has shown signs of the greatness of Allah SWT in the sky and grounded to prophet Ibrahim as so that his soul is directed. Then the prophet Ibrahim (as) discovered the truth of the belief in a Godhead through observation and contemplation about the universe by using his fitrah, and this is following verses 76-78. 2) Education of Uluhiyah Tauhid is in verse 74, which explains that the father and the prophets of Abraham made the idols they made into gods. Moreover, verse 79, that is, the sincerity of the prophet Ibrahim as to surrender, confronts his view of Allah SWT. It does not follow his people to associate Allah by way of worshiping other than Him, such as worshiping the stars, the moon, and the idols that they made themselves.3) Implementation of Tauhid Education in Islamic Education: The faith taught by Islam to humans since childhood is critical. Because the goals of Islamic education itself are in harmony with religious goals: 1) To realize a believer who believes and is devoted to Allah SWT.2) Education in Islam seeks to develop and inculcate monotheistic education to humans as optimal as possible to be able to function as a driving force in daily practice. 3) Development and inculcation of monotheism education can be done with learning activities, namely through various institutions. 4) In the school environment, both elementary, middle, and for the development and planting of monotheism, education is carried out through multiple activities, both at the time of KBM and extracurricular. 5) Outside the school, the development and cultivation of human monotheism education start from the family environment.
\end{abstract}

Keywords: Monotheism Education; Surat al-An'am; Islamic Education

Abstrak

Hasil penelitian menunjukkan bahwaPendidikan Tauhid dalam Surat Al-An'am:74-83 yaitu: 1) Pendidikan Tauhid Rubūbiyah (ayat 75), Allah SWT memperlihatkan tanda kebesaranNya dilangit dan dibumi kepada nabi Ibrahim as agar beliau terarah. Nabi Ibrahim menemukan aqidah Ketuhananmelalui pengamatan dan perenungan tentang alam raya menggunakan fitrahnya, sebagaimana ayat 76-78.2) Pendidikan Tauhid Uluhiyah (ayat 74), menerangkan bapak dan kaum nabi Ibrahim menjadikan berhalasebagai Tuhan.Nabi Ibrahim berserah diri kepada Allah SWT dan tidak mengikuti kaumnya mempersekutukanNya, sebagaimanaayat 79.3)Implementasi Pendidikan Tauhid dalam Pendidikan Islam:(1) 
mewujudkan seorang mukmin yang beriman dan bertaqwa kepada Allah SWT, (2) penanaman pendidikan tauhid seoptimal mungkin sebagai motor penggerak dalam praktik kehidupan sehari-hari, (3)pengembangan dan penanaman pendidikan tauhid pada sekolah formal dilakukan melalui berbagai kegiatan, baik saat KBM maupun ekstrakurikuler, dan (4) di luar sekolah pendidikan tauhid manusia diawali dari lingkungan keluarga. 5) Di luar sekolah pengembangan dan penanaman pendidikan tauhid manusia diawali dari lingkungan keluarga.

Kata kunci: Pendidikan Tauhid; Surat al-An'am; Pendidikan Islam

Menurut (Ali, 2008), Pendidikan adalah usaha sadar yang dilakukan manusia untuk mengembangkan potensi manusia lain dan norma yang dimilikinya kepada orang lain dalam masyarakat. Merujuk pada pengertian pendidikan di atas bahwa setiap manusia berhak untuk mengembangkan potensi dan mendidik orang lain agar dapat menyalurkan dan mengembangkan bakat yang dimilikinya. Selain itu, juga memiliki kemandirian dalam bersikap dan bertindak sehingga anak tersebut mempunyai rasa tanggung jawab atas dirinya sendiri.

Pendapat lain dari (Langeveld, 1976) mendenifisikan pendidikan sebagai setiap pergaulan yang terjadi antara orang dewasa dengan anak-anak dalam suatu keadaan dimana pekerjaan mendidik itu berlangsung.Pendidikan adalah bimbingan atau pimpinan secara sadar oleh si pendidik terhadap perkembangan jasmani dan rohani peserta didik menuju terbentuknya kepribadian yang utama (Marimba, 1989).

Menurut (Daulay, 2004) pendidikan Islam adalah pendidikan yang bertujuan untuk membentuk pribadi muslim seutuhnya, mengembangkan seluruh potensi manusia baik yang berbentuk jasmani dan rohani, serta menumbuhkan hubungan yang harmonis setiap individu dengan Allah SWT, manusia lain, dan alam semesta.Pendidikan Islam sebagai alat untuk proses penyampaian informasi dalam rangka pembentukan insan yang beriman dan takwa agar manusia menyadari kedudukan, tugas dan fungsinya di dunia ini baik sebagai abdi maupun sebagai khalifah-Nya di bumi.

Selain itu, (Arifin, 2014) mengemukakan pendidikan Islam juga berorientasi untuk mengarahkan dan membimbing pertumbuhan serta mengembangan fitrah (kemampuan dasar) 
anak didik melalui ajaran Islam ke arah titik maksimal pertumbuhan dan perkembangannya. Karena, agama Islam merupakan way of life yang menjamin kebahagiaan hidup pemeluknya di dunia dan di akhirat agama Islam sebagai suatu konsep kehidupan yang mempunyai landasan yang khas dan spesifik dibandingkan dengan agama lainnya. Karena komponen utama agama Islam yaitu akidah, syari'ah dan akhlak yang kemudian dikembangkan oleh manusia dengan akal pikiran mereka yang didorong dengan ilmu pengetahuan.

Al-Qur'an merupakan kitab suci yang dijadikan pedoman umat Islam dalam melaksanakan ajaran agama Islam. Di dalam Al-Qur'an terdapat isi ajaran yang menyeru pada tauhid atau keimanan sejak diutusnya Nabi Adam as sampai Nabi Muhammad saw. Dalam memahami maksud firman-firman Allah SWT sesuai dengan kemampuan manusia itulah yang disebut tafsir (Shihab, 1996).

Masalah keyakinan atau tauhid memang sangat penting dalam kehidupan beragama, sebab seseorang sebelum memeluk suatu agama haruslah ia terlebih dahulu yakin serta percaya dengan agamanya sendiri. Ajaran tauhid merupakan inti dari ajaran agama Islam yang dijadikan sebagai dasar bagi pembentukan karakter, serta pengembangan kepribadian semua orang.Pendidikan tauhid menurut (Majid, 2014) adalah seluruh kegiatan umat manusia di bidang pendidikan yang menempatkan Allah sebagai sumbernya, karena Dia adalah Tuhan Rabb al-'Alamin.

Menurut Dahlan bidang tauhid yang menekankan sisi keesaan Allah dengan semurnimurninya dan sebenar-benarnya, disebut dengan istilah tauhid al-'uluhiyah.Dalam pengertian ini, Tuhan adalah predikat kepada Zat yang wajib diyakini dan diimani oleh semua manusia.Adapun bidang tauhid yang menekankan sisi kewajiban seorang hamba untuk senantiasa menunjukkan pengakuan kehambaannya kepada Tuhan, disebut dengan tauhid al'ubudiyyah (Dahlan, 1997).Untuk memenuhi pengertian tauhid ini seorang hamba dituntut menunjukkan keikhlasan dan kemurnian pengabdiannya semata-mata kepada Allah SWT.Secara manusiawi manusia memiliki kecenderungan untuk meragukan sesuatu karena manusia diberi akal pikiran.Bahkan dalam Q.S. Al-An'am ayat 74-83 di jelaskan bahwa Nabi Ibrahim as menemukan dan membina keyakinannya melalui pencaharian dan pengalamanpengalaman keruhanian yang dilaluinya.Dalam menyikapi semua keraguan itu, kita dapat 
mengatasinya dengan mendalami pemahaman tentang agama yang kita anut. Berdasarkan uraian tersebut, penulis akan mendeskripsikan dan menganalisa bagaimana pendidikan tauhid dalam Kisah Nabi Ibrahim.

\section{Metode}

Metode dalam penelitian ini adalah kualitatif dalam kajian Kepustakaan. Kajian kepustakaan (library research) yang dilakukan dengan menghimpun data dari berbagai literatur untuk menemukan berbagai teori, hukum, dalil, prinsip-prinsip, pendapat, gagasan, dan lainlain (Nawawi, 2012). Data-data literatur ini dikumpulkan melalui metode dokumentasi (Arikunto, 2010), sehingga penulis memperoleh informasi bukan dari orang sebagai narasumber, tetapi dari macam-macam sumber tertulis (Bloor dan Wood, 2006). Adapun caracara dalam pengumpulan datanya diantaranya; Pertama, melakukan kajian pustaka yang sesuai dengan bahan yang diteliti. Kedua, setelah data diperoleh, maka penulis melakukan analisis dengan metode tahili. Metode tahili dapat diartikan sebagai cara menjelaskan arti dan maksud ayat-ayat al-Qur'an dari sekian banyak seginya, dengan menjelaskan ayat demi ayat sesuai urutan-urutannya di dalam mushhaf, melalui penafsiran kosa kata (ma'an al-mufradat), penjelasan asbab al-nuzul (sebab-sebab turunya suatu ayat), munasabat (keterkaitan ayat dengan ayat, surat dengan surat, dan seterusnya), serta kandungan ayat tersebut, sesuai keahlian dan kecenderungan seorang mufassir (Harahap, 2000).

\section{Hasil dan Pembahasan}

\section{Pendidikan Tauhid Telaah Kisah Ibrahim as dalam Surat Al-An'am ayat 74-83}

Pada pembahasan ini penulis akan memaparkan analisis pendidikan tauhid sesuai pada ayat-ayat yang dikaji yaitu, pada surat Al-An'am ayat 74-83 sebagai berikut:

Pendidikan Tauhid Rubūbiyah

Pendidikan tauhid rubūbiyah yang terdapat pada ayat 75 yang menerangkan bahwasanya Allah SWT telah memperlihatkan tanda-tanda kebesaran Allah SWT dilangit dan dibumi kepada nabi Ibrahim as agar jiwa beliau terarah. Dan dengan melihat keindahan ciptaan Allah itulah, beliau akan mendapatkan bukti-bukti ke Esaan-Nya. 
Nabi Ibrahim as menemukan kebenaran aqidah Ketuhanan Yang Maha Esa melalui pengamatan dan perenungan tentang alam raya dengan menggunakan fitrahnya, hal ini sesuai dengan ayat 76-78. Dari beliau melihat dan mengamati bintang, bulan dan matahari serta perenungannya maka disimpulkan bahwa beliau tidaklah menyukai sesuatu yang tenggelam atau hilangberkeyakinan bahwa semua itu diciptakan oleh sesuatu yang kekal yaitu Allah SWT.

Karena iman seseorang itu tidak tumbuh dengan sendirinya, melainkan diasah dan dipertebal dengan cara terus-menerus menggali rahasia kekuasaan Allah SWT yang tersedia di alam semesta (Assegaf, 2014).

Pendidikan Tauhid Uluhiyah

Pendidikan tauhid uluhiyah ini terdapat pada ayat 74 yang dijelaskan bahwasanya bapak dan kaum nabi Ibrahim as menjadikan berhala yang mereka buat itu dijadikan sebagai tuhan.

Dan ayat 79 yaitu, keikhlasan nabi Ibrahim as untuk berserah diri kepada Allah SWT dan tidak mengikuti kaumnya untuk mempersekutukan Allah dengan menyembah seperti bintang, bulan dan berhala-berhala yang mereka buat sendiri. Karena berhala-berhala yang mereka buat sama derajatnya dengan yang menciptakan.

Pendidikan Tauhid menurut Analisis Psikologi Islam

Keyakinan tauhid Nabi Ibrahim as. dilatarbelakangi kondisi kehidupan psikososial dan religiusitas yang menyimpang, baik di lingkungan masyarakatnya maupun lingkungan kelurganya sendiri. Kondisi tersebut menyebabkan masyarakat berada dalam kebodohan dan ketundukan tanpa syarat. Kebodohan ini terlihat dari kecenderungan mereka pada kehidupan yang berresiko, kedzaliman, dan sikap atautindakan impulsif yang tidak didasari pertimbangan rasional dan kritis (Ashshiddiqi, 2017).

Masalah moral dan sosial sering muncul dari situasi dan kondisi kehidupan semacam ini. Indikasi yang kuat ditemukan pada kehidupan psiko-spiritual dan religiusitas masyarakat Nabi Ibrahim as., seperti kepercayaan buta terhadap berhala sebagai Tuhan dan sesembahan, dan ramalan bintang sebagai dasar keputusan tindakan dari pada ilmu dan pengetahuan (Ashshiddiqi, 2017).

Nabi Ibrahim as. sendiri mengalami pertumbuhan fisik serta perkembangan psikis yang pesat setelah kelahirannya. Rasa ingin tahu, daya kritis dan pemikiran rasional, sudah 
ditunjukkan Nabi Ibrahim as. sejak masamasa kecilnya. Sejak masa-masa ini pula Nabi Ibrahim as. sudah menunjukkan minat yang besar terhadap pengetahuan tentang Tuhan. Minat Nabi Ibrahim as. ditunjukkan melalui analisis yang berkembang dengan pengamatan dan aktivitas bertanya tentang fenomena alam, sosial, moral dan spiritual (Ashshiddiqi, 2017).

Kecenderungan Nabi Ibrahim as. untuk mengimani yang mutlak dan mengingkari bendabenda mati adalah suatu kenyataan fitrah yang ada dalam dirinya. Sedangkan aktivitas akalnya dalam berpikir mencari kebenaran tentang yang mutlak tersebut adalah kenyataan fitrah yang lain pada dirinya. Esensi kedua kenyataan itu adalah sama dan menyatu (Ashshiddiqi, 2017).

Menurut Al Faruqi (1988) iman danberpikir pada hakikatnya bersifat agamawi dan merupakan bagian dari sunnatullah, yang sejak awal melekat pada kehadiran manusia di muka bumi. Manusia mempunyai motif ingin tahu sebagai tabiat yang menggerakkannya untuk meneliti, mengungkapkan sebab akibat dari apa saja fenomena yang menarik perhatiannya.

Secara khusus, Nabi Ibrahim as. melakukan evaluasi kritis dengan memanfaatkan bukti yang ditemukannya. Pada tahap akhir, pengetahuan secara aktif dibangun oleh Nabi Ibrahim as. dengan berbagai upaya interaksionis dan konstruktivis, lalu pengetahuan dan kebenaran yang diperolehnya berkembang dan muncullah justifikasi. Menurut (Ashshiddiqi, 2017) pada tahap akhir ini justifikasi yang dimaksud telah melibatkan wahyu Tuhan yang sesuai dengan pemikiran kritis dan pertimbangan hati nurani.

\section{Implementasi Pendidikan Tauhid dalam Pendidikan Islam}

Setelah penulis membahas pendidikan tauhid telaah kisah nabi Ibrahim as dalam surat Al-An'am ayat 74-83, maka penulis akan menyajikan implementasi pendidikan tauhid dalam pendidikan Islam, yaitu sebagai berikut:

Keimanan yang diajarkan agama Islam pada manusia sejak kecil sangatlah penting. Karena tujuan pendidikan Islam itu sendiri selaras dengan tujuan agama untuk: 1. mewujudkan seorang mu'min yang beriman dan bertaqwa kepada Allah SWT. Secara umum memang pendidikan Islam diantaranya pembahasan tentang ketauhidan karena, pendidikan tauhid merupakan hal yang dasar atau utama yang harus tertaman pada diri manusia.Misalnya melaksanakan segala perintah Allah SWT dan menjauhi segala larangan-Nya.2.Pendidikan 
dalam Islam berusaha untuk mengembangkan dan penanaman pendidikan tauhid kepada manusia seoptimal mungkin untuk dapat difungsikan sebagai motor penggerak dalam praktek kehidupan sehari-hari. Jadi apapun yang kita lakukan haruslah berlandaskan dengan keimanan kita.Suatu contoh apapun yang kita lakukan diawali dengan membaca "Basmallah" (kita menyandarkan segala sesuatu hanya kepada Allah). 3. Dan dalam peribadatan-Nya menekankan tidak menyekutukan-Nya. Misalnya: menghindari hal-hal yang bersifat musyrik. 4. Pengembangan dan penanaman pendidikan tauhid dapat dilakukan dengan kegiatan belajar, yaitu melalui berbagai institusi. Belajar yang dimaksud tidak berfokus melalui pendidikan di sekolah saja, tetapi juga dapat dilakukan di luar sekolah, baik dalam keluarga, masyarakat, maupun melalui institusi sosial keagamaan yang ada. 5. Pada lingkungan sekolah baik dasar, menegah, dan atas pengembangan dan penanaman pendidikan tauhid dilakukan melalui berbagai kegiatan, baik pada saat KBM maupun ekstrakurikuler. Saat KBM siswa dididik untuk menjadi siswa yang kuat imannya.6.Di luar sekolah pengembangan dan penanaman pendidikan tauhid manusia diawali dari lingkungan keluarga. Orang tua mendidik anaknya untuk menjadi kokoh imannya.Sedangkan di lingkungan masyarakat terdapat pula berbagai kegiatan yang dapat mengembangkan dan menanamkan pendidikan tauhid melalui pengajaran di TPQ dan majelis taklim.

\section{Kesimpulan}

Pendidikan tauhid rubūbiyah yang terdapat pada ayat 75 yang menerangkan bahwasanya Allah SWT telah memperlihatkan tanda-tanda kebesaran Allah SWT dilangit dan dibumi kepada nabi Ibrahim as agar jiwa beliau terarah.Dan nabi Ibrahim as menemukan kebenaran aqidah Ketuhanan Yang Maha Esa melalui pengamatan dan perenungan tentang alam raya dengan menggunakan fitrahnya, hal ini sesuai dengan ayat 76-78.Sedangkan, Pendidikan Tauhid Uluhiyah terdapat pada ayat 74 yang dijelaskan bahwasanya bapak dan kaum nabi Ibrahim as menjadikan berhala-berhala yang mereka buat itu dijadikan sebagai tuhan. Dan ayat 79 yaitu, keikhlasan nabi Ibrahim as untuk berserah diri menghadapkan pandangan beliau kepada Allah SWT dan tidaklah mengikuti kaumnya untuk mempersekutukan Allah dengan cara menyembah selain-Nya seperti menyembah bintang, bulan dan berhala-berhala yang mereka buat sendiri. 
Sedangkan implementasi pendidikan tauhid dalam pendidikan Islam yaitu Keimanan yang diajarkan agama Islam pada manusia sejak kecil sangatlah penting. Karena tujuan pendidikan Islam itu sendiri selaras dengan tujuan agama untuk: (1) mewujudkan seorang mu'min yang beriman dan bertaqwa kepada Allah SWT. (2) Pendidikan dalam Islam berusaha untuk mengembangkan dan penanaman pendidikan tauhid kepada manusia seoptimal mungkin untuk dapat difungsikan sebagai motor penggerak dalam praktek kehidupan seharihari. (3) Dan dalam peribadatan-Nya menekankan tidak menyekutukan-Nya. (4) Pengembangan dan penanaman pendidikan tauhid dapat dilakukan dengan kegiatan belajar, yaitu melalui berbagai institusi. (5) Pada lingkungan sekolah baik dasar, menegah, dan atas pengembangan dan penanaman pendidikan tauhid dilakukan melalui berbagai kegiatan, baik pada saat KBM maupun ekstrakurikuler. (6) Di luar sekolah pengembangan dan penanaman pendidikan tauhid manusia diawali dari lingkungan keluarga.Kebaruan dari penelitian ini bahwasanya pendidikan tauhid dapat diajarkan dengan menanamkan nilai-nilai ketauhidan dengan pembelajaran diluar.Melihat dan menganalisis fenomena yang ada di lingkungan sekitar tanpa harus dengan teoritis di pembelajaran diruangan.

Saran

Kajian dalam penelitian ini menggunakan kajian literatur yang hanya terfokus pada surat al-an'am ayat 74-83, sehingga pada peneliti selanjutnya dapat menelaah pendidikan tauhid menggunakan versi surat-surat al-Qur'an ataupun literatur yang lain. Serta Pembelajaran utamanya tentang katauhidan perlu kiranya dengan mengkolaborasikan antara pembelajaran dalam keluarga, sekolah dan lingkungan masyarakat.

\section{Referensi}

Al Faruqi, I. R. 1984. Islamisasi pengetahuan, Terj. A. Mahyuddin, Bandung: Pustaka.

Al Maraghi, A. M. 1992. Terjemahan tafsir Al Maraghi juz VII. Semarang: Toha Putra Semarang. Al Qarni, A. 2008. Tafsir muyassar. Jakarta: Qisthi Press.

Ali, M. D. 2008. Pendidikan Agama Islam, Jakarta: Raja Grafindo Persada.

Ashshiddiqi, A. M. 2017. Model epistemologi personal dalam keyakinan tauhid Nabi Ibrahim As (Perspektif Psikologi dan Islam), PSYMPATHIC : Jurnal Ilmiah Psikologi, 4 (1). 
Ash Shiddieqy, T. M. H. 2000. Tafsir Al Qur'anul Majid An-Nuur Juz 7. Semarang: PT Pustaka Rizki Putra.

Departemen Agama R.I. (2002). Al Qur"an dan Terjemahnya, Madinah: Lembaga Percetakan Al Quran Raja Fahd.

Arifin, M. 2014. Ilmu pendidikan Islam: Tinjauan teoritis dan praktis berdasarkan pendekatan interdisipliner. Jakarta: PT Bumi Aksara.

Arikunto, S. 2010. Prosedur penelitian: Suatu pendekatan praktek, Jakarta: Rineka Cipta.

Bloor, M. \& Wood, F. 2006. Keywords in qualitative methods: A Vocabulary of Research Concepts, New Delhi: SAGE Publications.

Daulay, H. P. 2004. Pendidikan Islam: Dalam sistem pendidikan nasional di Indonesia. Jakarta: Kencana.

Dahlan, A. R. 1997. Kaidah-kaidah penafsiran Al-Qur'an.Bandung : Mizan.

Harahap, Sahrin. 2000. Metodologi studi dan penelitian ilmu-ilmu ushuluddin. Jakarta: PT Raja Grafindo Persada.

Langeveld, M. J. 1976. Paedagogik: Teoritis-Sistematis. Jakarta: IST.

Majid, A. 2014. Pendidikan berbasis ketuhanan: Membangun manusia berkarakter. Bogor: Ghalia Indonesia.

Marimba, A. D. 1989. Pengantar Filsafat Pendidikan Islam. Bandung: PT. Al-Ma'arif.

Nawawi, H. 2012. Metode penelitian bidang sosial. Yogyakarta: Gadjah Mada University Press.

Shihab, M. Q. 1996. Wawasan Al-Quran: Tafsir maudhu'i atas pelbagai persoalan umat. Bandung: Mizan. 